\title{
Nuevas formas y procesos espaciales en el territorio contemporáneo: la "ciudad única""
}

\author{
Eduardo De Santiago Rodríguez*
}

Resumen: El nuevo régimen de acumulación emergente que viene construyéndose lentamente desde mediados de los años 70 y de forma más acelerada aún durante la última década, exige requerimientos espaciales para su despliegue que -con ligeros matices localespueden ser observados en la mayoría de las ciudades y los territorios metropolitanos de los países desarrollados. A este nuevo modelo espacial y de gestión urbana resultante le denominamos "ciudad única", para incidir en su obediencia y sometimiento al proyecto hegemónico social, económico, cultural y político del pensamiento único.

La estructura espacial del territorio contemporáneo resultante de este modelo debe ser entendida desde la superposición de tres estratos: el espacio de los lugares (paisajes naturales y territorios antropizados en diferentes grados, desde los paisajes rurales a los territorios urbanos), el espacio de las redes (compuesto por las líneas y vectores de flujos y los nodos de intercambio) y el "campo rizomático de los flujos inmateriales".

Más allá de las meteóricas espectaculares y fotogénicas transformaciones urbanas que se suceden en los espacios que resultan "ganadores" o beneficiados en el nuevo régimen de acumulación, en esta nueva estructura espacial se manifiestan numerosas contradicciones, conflictos, desigualdades, e injusticias que apenas son desveladas por el discurso hegemónico imperante.

Palabras clave: Ciudad única, estructura espacial, territorio red, espacio de los lugares, campo rizomático.

\section{New forms and spacial proceses in conttemporary territory: the "unique city"}

\begin{abstract}
The new emerging "accumulation regime" which is being built since the mid70 's and even more rapidly over the last decade, requires some space

\footnotetext{
* Este artículo se basa en la comunicación "Nuevos paisajes metropolitanos: del paisaje figurativo al paisaje-red", presentada al Congreso Europeo sobre Investigación Arquitectónica y Urbana EURAU’08 Paisaje Cultural, organizado por la Escuela Técnica Superior de Arquitectura de la Universidad Politécnica de Madrid ETSAM/UPM en colaboración con la Escuela Nacional Superior de Arquitectura de Marsella ENSA, la Escuela Nacional Superior de Arquitectura y Paisaje de Lille y la Asociación de Institutos Superiores de Arquitectura de Bruselas, Lieja y Mons ISAI, con el apoyo del Ministerio de Educación y Ciencia de España. En él se recogen algunos temas tratados en la Tesis Doctoral del autor, titulada "Nuevas formas y procesos espaciales en la región urbana de Madrid ": Las lógicas del espacio en la construcción de la "Ciudad Única", dirigida por Ramón López de Lucio y que fue leída en la ETSAM el 19/06/2006, obteniendo Sobresaliente Cum Laude y el Premio Extraordinario de Tesis Doctoral de la Universidad Politécnica de Madrid. 2005-2006.

*** Universidad de Alcalá, Madrid, España. Email: ed.desantiago@telefonica.net
} 
requirements for its deployment that can be observed -with subtle differences- in most cities and metropolitan areas of the developed countries all around the world. We call this new spatial and urban management model the «only-city», so as to stress its obedience and submission to the hegemonic social, economic, cultural and political project which has been named as "the only-way-of-thinking".

The spatial structure of nowadays territory can only be understood by the overlapping of the "space of places" (natural landscapes and anthropic territories, in different degrees, from rural landscapes to urban territories), the "network space" (composed of flow lines and exchange nodes) an the "rhizomatic field of inmaterial flows".

Beyond the spectacular meteoric and photogenic transformations taking place in urban spaces which have become the «winners» or beneficiaries in this new accumulation regime, in this new spatial structure arise numerous contradictions, conflicts, inequalities and injustices that are barely unveiled by the hegemonic discourse. field.

Keywords: Exclusive city, spatial structure, network space, space of places, rhizomatic

Recibido: 01.07 .08

Aceptado: 21.07.08

$* * *$

\section{Los rasgos del nuevo régimen de acumulación. El nuevo "paradigma único"1}

A mediados de los años 70 entró en crisis el viejo paradigma que había sido dominante en Europa occidental (y que fue tomado como referente en muchos otros países) durante las tres décadas posteriores a la Segunda Guerra Mundial y que se formuló con la ecuación "Democracia, Capitalismo keynesiano-fordista y Bienestar". Esta crisis también arrastró consigo al modelo económico y social propio de dicho paradigma, que había presidido la construcción de las áreas metropolitanas en buena parte de los países "desarrollados".

El largo camino recorrido desde aquel punto de inflexión hasta la actualidad otros 30 años- puede leerse (aun a pesar de la existencia de ciertos momentos de desconcierto, incertidumbre o incluso de ligeras derivas en otras direcciones) como el avance en la senda, con pasos cada vez más seguros y menos cuestionados, hacia un nuevo "paradigma único"2 que se ha ido formulando o desvelando paralelamente y de manera progresiva en el ámbito global hasta hacerse hegemónico e incuestionado en buena parte del "mundo desarrollado".

A grandes rasgos, y con distintos matices o versiones locales, este nuevo paradigma único arranca de la última mutación del capitalismo

\footnotetext{
${ }^{1}$ En referencia al "pensamiento único", expresión acuñada por el periodista Ignacio Ramonet en el Editorial La pensée unique, en Le Monde Diplomatique, en el año 1995.

${ }^{2}$ Con cierta variedad dentro de la "unicidad", que no uniformidad.
} 
desde su vieja versión keynesiana fordista a la neoliberal; lo que implica la sustitución del paradigma del control social de la economía por el del mercado como mecanismo supuestamente autorregulado, y la retirada del Estado de la economía tanto como regulador (desregulación) como agente directo (privatizaciones), vaciamiento de funciones que ha sido sustituido por un nuevo papel entrepreneurial o promocional; todo ello en un contexto de férrea disciplina macroeconómica (control del gasto y déficit públicos). Por su parte, el nuevo modelo de acumulación emergente resulta derivado de una serie de procesos que han ido convergiendo hasta hacerse paralelos, al tiempo que globalmente se formulaba una nueva división internacional del trabajo (extendiendo e intensificando las relaciones asimétricas de dominación existentes entre países y nodos): el desbordamiento de los espacios de acumulación nacional y la interdependencia planetaria de los procesos de acumulación (globalización); la revolución tecnológica denominada informacional; el deslizamiento desde una economía de productos a una de funciones (frecuentemente enunciado de manera imprecisa como "terciarización postindustrial"), la orientación de los procesos industriales hacia la producción flexible; la irrupción y el protagonismo adquirido por una "nueva economía" pretendida pero falazmente inmaterial (economía financiera, decisional e informacional), etc.

Todo esto se ha acompañado con importantes transformaciones en el modelo empresarial (generalización de la empresa red) y, de manera muy significativa, con una trituración, segmentación y polarización de aquella relativa continuidad del universo laboral fordista y de las condiciones sociales de amplios estratos de trabajadores (fenómenos eufemísticamente resumidos en el concepto de "flexibilización laboral"), todo lo cual ha implicado una verdadera centrifugación y polarización de las estructuras sociales existentes, pues éstas siguen estando principalmente definidas o "determinadas" por las relaciones laborales y salariales, de modo que las transformaciones en el mundo del trabajo han tenido un reflejo inmediato en el mosaico social.

Por su parte, el último término de la ecuación -el Estado del Bienestar- también ha sido radicalmente cuestionado, al tiempo que sus políticas de equilibrio social van siendo progresivamente erosionadas o mercantilizadas.

\section{El enunciado de la "ciudad única”}

La dimensión urbana de este nuevo paradigma, o, lo que es lo mismo, los requerimientos espaciales del nuevo modelo, pueden enunciarse bajo el concepto de "ciudad única". En primer lugar, la "unicidad" se fundamentaría en la asunción (bien como positiva, inevitable o incuestionable) de la lógica funcional de la acumulación actual en los términos sostenidos por el "pensamiento único", primando las estrategias de la eficiencia y la competitividad económica que le caracterizan. 
En segundo lugar, y en relación con el ya tradicional entendimiento de la ciudad como máquina o soporte de la acumulación, se trataría de materializar -profundizando en la especialización y segmentación del territorio según sus "ventajas competitivas"los nodos de acumulación del nuevo paradigma (núcleos de conexión con la economía decisional, financiera e informacional; nodos logísticos; centros de la gran distribución y del consumo masivo; nuevas plantas productivas, etc.) y las líneas de conexión entre estos nodos, que permiten la movilidad de los flujos físicos (infraestructuras de conexión lejana, puertos, aeropuertos, logística, etc.), de los recursos humanos/turistas/consumidores (ferrocarriles de alta velocidad, aeropuertos, redes viarias y transportes públicos metropolitanos) y de los flujos inmateriales (cableado de interconexión y despliegue del campo rizomático o ciberespacio). Este requerimiento se resumiría en el paso de los tradicionales territorios zona al territorio red (Veltz 1999), articulador topológico de los nodos donde se concentra la acumulación en base a estructuras reticulares conectivas.

En tercer lugar, sería la propia ciudad -y la vivienda- la que, más allá de su valor de uso, pasaría a entenderse como mero espacio de acumulación, prevaleciendo su valor de cambio y convirtiéndose en un gran "armatoste" inmobiliario para la acumulación en forma de patrimonio construido del ahorro familiar (Roch 1999) mediante la capitalización de las rentas salariales (para la mayoría), o de inversión de los excedentes (para una minoría, local o foránea), generando y exigiendo espirales y burbujas de expectativas crecientes, bienvenidas por los sectores inmobiliarios y el financiero que aprovecharían sabiamente a su favor esta renovada rentabilidad del negocio inmobiliario.

Esta dimensión ha buscado -y ha obtenido, al menos hasta la crisis hipotecaria desatada en EEUU en 2007- mecanismos que garantizasen en el tiempo la estabilidad de la acumulación inmobiliaria, y unas tasas de rentabilidad creciente para la inversión. Es por ello que se ha conjugado perfectamente con el proceso paralelo de reorganización depurativa del espacio social que veremos a continuación, pues la finalidad de ambos no ha sido sino el establecimiento y la consolidación del precio de la vivienda como mecanismo de exclusión, selección y filtrado social, lo que ha garantizado durante el boom inmobiliario internacional esa estabilidad requerida y -en un contexto de fuerte competencia para ubicarse o reubicarse en el mapa social de la ciudad- ha contribuido a impulsar su crecimiento, satisfaciendo así las dos condiciones exigidas.

En relación con la reorganización del espacio social de la ciudad -entendida ésta como soporte físico ${ }^{3}$ del orden social-, y considerando la mencionada centrifugación o polarización de las estructuras sociales

${ }^{3}$ A. Lipietz afina esta visión, introduciendo la idea del espacio como molde social. 
derivada de la reestructuración del mercado laboral (aparición simultánea de grandes, medianos y pequeños ganadores, frente a los perdedores, subempleados e inmigrantes), se trataría de depurar las lógicas del viejo espacio social heredado del paradigma anterior (relativamente continuo y variado), afinando en la exclusión y clasificación de los individuos en los nichos espaciales que socialmente les son asignados de un modo más "conveniente" a esa reciente polarización, ${ }^{4}$ bien mediante la producción de nuevas formas espaciales segregadas (urbanizaciones cerradas, enclaves elitizados, procesos de "suburbanización popular" para los medianos ganadores, etc.), bien por la reestructuración más o menos traumática del espacio social de la ciudad consolidada (elitizaciones de diverso alcance, aparición de espirales de degradación y formación de sumideros o ghettos, etc.).

Otro rasgo de la "ciudad única" sería la redefinición de las lógicas de poder que operan en el régimen urbano. Así, además de la forja de nuevas alianzas y contradicciones entre los agentes privados (cuestión que tiene implicaciones muy locales, difícilmente generalizables y que requieren un examen concreto en cada ciudad), la Administración estaría reorientando su papel regulador hacia un nuevo papel promocional, primando casi siempre la acción de los agentes privados y sustituyendo su acción directa por la simple participación en fórmulas mixtas. ${ }^{5}$ En el sentido de la desregulación, sería notable la erosión de la credibilidad en el planeamiento estructurante, sustituido por la planificación estratégica. Mientras, en el sentido promocional, resultarían prácticas habituales el fomento de la competitividad entre ciudades y el marketing urbano; pero también la construcción de infraestructuras y la urbanización pública de suelo para actividades económicas.

Finalmente, el Plan como instrumento de intervención sobre la totalidad estaría siendo sustituido por toda una panoplia de estrategias sectoriales o parciales y de proyectos fragmentarios, combinados como mágicas fórmulas alquímicas, aplicados como recetas urbanas de uso tópico, como bálsamos de Fierabrás capaces de purgar (supuestamente) los males de la ciudad heredada y de operar su metamorfosis, cuando no su transubstanciación. Este recetario incluiría: "grandes proyectos emblemáticos", la creación de infraestructuras duras de conexión funcional con el sistema global (redes de transporte y núcleos direccionales), estrategias de incremento de la calidad de vida y maquillaje de la imagen urbana (nuevos espacios residenciales para los estratos medios y altos, adecuación del paisaje periférico y reciclaje visual y cultural del territorio herido), organización de macroeventos, incentivos empresariales, etc.

\footnotetext{
${ }^{4}$ Lo que significa la exclusión de los desiguales, para asegurar -supuestamente- la reproducción en el tiempo de las estructuras sociales consolidadas y evitar -hipotéticos- conflictos en el espacio derivados del desorden social que -supuestamente- produciría la mezcolanza.

${ }^{5}$ En las cuales muchas veces su papel es poco más que el darles legitimidad o garantías.
} 


\section{La nueva estructura espacial como superposición del espacio de los lugares, el espacio de las redes, y el campo rizomático}

Siguiendo la línea argumental de Weber, Geddes y Braudel recogida por J. M. Naredo (2000), puede decirse que la traducción espacial de las estructuras funcionales del régimen de acumulación hegemónico actual requiere la organización reticular del espacio en base a nodos, nódulos o densificaciones (que son los distintos organismos capaces de acumular: regiones, ciudades, empresas, etc.) interconectados por líneas de conexión funcional, que permiten la parasitación de los recursos necesarios allí donde se encuentran, para llevarlos a los nodos y redistribuirlos desde ellos una vez recombinados, tarea que implica la circulación o el transporte de flujos (recursos naturales o energéticos, materiales, etc.) necesarios para el metabolismo y la alquimia combinatoria que se producen en los nodos. En base a esta idea, la ciudad puede entenderse como una gran máquina de parasitación que extiende sus tentáculos (Geddes) depredadores a otros territorios en los cuales materializa las funciones de apropiación y vertido; para lo cual necesita también convertirse en una máquina de dominio (Weber, Braudel) ${ }^{6}$ militar, político, cultural, etc. A ello se superpone actualmente un espacio propio para el acceso a los flujos inmateriales (y muy especialmente a la información, las consignas culturales homogeneizado-ras y los flujos financieros): el "campo rizomático", un espacio inmanente y ubicuo, donde más que "circular" residen múltiples contenidos que son accesibles desde cualquier punto del espacio mediante el uso de una sofisticada utilería de emisión / recepción (teléfonos móviles, ordenadores, antenas, etc.) que apenas precisa materializar físicamente líneas infraestructurales. De esto modo, para nosotros, la estructura espacial del territorio contemporáneo que se deriva de la transposición espacial de las lógicas de la acumulación actual puede definirse por la superposición interactiva de tres sistemas espaciales, cada uno con sus dinámicas propias y provocando distintas interferencias o relaciones entre sí: el espacio de los lugares, correspondiente tanto a los espacios geográficos (al medio natural), como a los espacios rurales y urbanos tradicionales; el espacio de las redes, y el campo rizomático de los flujos inmateriales.

\section{El espacio de los lugares}

Es el espacio tradicional, accesible para las personas, dominable y apropiable por los individuos, donde la posibilidad de presencia permite (en términos kantianos) la posibilidad de coexistencia. Está basado en la

\footnotetext{
${ }^{6}$ Herce y Magrinyá (2002: 8) recogen así la idea de Braudel "la ciudad debía controlar una superficie agrícola periurbana, cuya importancia dependía directamente de la población urbana a que podía alimentar; la autonomía urbana no se podía asegurar más que por el dominio de la producción agrícola de los alrededores y por el control de las vías que conectaban la zona agrícola con la ciudad".
} 
geometría euclídea, la percepción fenomenológica regida por las leyes clásicas de la perspectiva, y en él funcionan los mecanismos de apropiación espacial y simbólica, colonización, gradiente público-privado, etc.

Aunque cada vez es más difícil (y quizá menos operativo), todavía es posible distinguir dos grandes categorías de lugares: los territorios naturales (definidos fundamentalmente por sus características abióticas y bióticas no antrópicas-vegetación y fauna-) y los territorios antropizados, en mayor o menor grado, con un amplio gradiente que va desde las categorías tradicionales de los territorios o los paisajes rurales a las distintas formas de urbanización o formas de crecimiento urbano (asentamientos rurales, núcleos históricos, polígonos de bloque abierto, tejidos suburbanos, etc.). Para leer estos territorios antropizados en cada caso concreto se debe atender al cruce de las dinámicas morfogenéticas que los han originado con los procesos de Urbanización (entendida como definición de la red soporte de la estructura conectiva), Parcelación (entendida como definición del mosaico) y Edificación $(\mathrm{U}+\mathrm{P}+\mathrm{E})$ establecidos por $\mathrm{M}$. Solá Morales (1997).

\section{Las formas espaciales de los nuevos lugares-nodos de acumulación}

Como hemos apuntado, el nuevo modelo de acumulación emergente ha significado una profunda transformación de las bases productivas de la ciudad, con la aparición de nuevas actividades emergentes (servicios avanzados terciarios, turismo, grandes superficies comerciales, logística, etc.) y el desmantelamiento de algunas tradicionales (como la industria o el pequeño comercio). En el espacio de la ciudad esto ha supuesto el desarrollo "ex novo" de formas espaciales específicas para albergar estas actividades, tales como parques empresariales, grandes contenedores monofuncionales especializados (hipermercados, centros comerciales, centros de ocio, multicines, etc.), parques logísticos e industriales, etc. Pero también la renovación o transformación de la ciudad existente para adecuarla a los requerimientos de nuevo modelo.

La mayor parte de las formas espaciales emergentes en que se materializan los nuevos nodos de acumulación comparten una serie de características comunes. En primer lugar destaca su carácter especializado y frecuentemente monofuncional o monotemático, enunciado bajo la fórmula de los "parques"... empresariales, comerciales, de ocio (temático), o de las "ciudades"... empresarial, universitaria, sanitaria, etc. En los casos más sofisticados, y partiendo de la exitosa fórmula de la definición a partir del marketing del mix óptimo de actividades en un centro comercial, se definen fórmulas de "usos mixtos" en los que la variedad está definida artificialmente para lograr sinergias entre las actividades propuestas, pero donde se excluyen buena parte de las actividades urbanas tradicionales, se filtran o se depuran con el objeto de que no existan imprevisiones que puedan interferir con el objetivo propuesto. En el fondo, mediante la hiperespecialización del espacio, se intenta no sólo adaptarse más 
fiel y eficazmente a una determinada función, sino también configurar modelos urbanos funcionalmente cerrados y predeterminados donde la implantación espontánea de otras actividades (propia de la ciudad tradicional) introduciría rasgos de imprevisión e incertidumbre que son indeseables. Desde este punto de vista, se renuncia al enriquecimiento funcional que supone la evolución vital y la sedimentación a lo largo del tiempo en la ciudad convencional, eliminando los supuestos riesgos que podrían derivarse de una evolución libre (degradación funcional, obsolescencia, marginalización, etc.), pretendiendo quizá con ello sustraer de la línea del tiempo, perpetuar esas fórmulas urbanas destiladas con absoluta -e ingenua- precisión científica en los laboratorios urbanísticos. Análogamente, desde el punto de vista social son espacios excluyentes, con barreras y accesos restringidos mediante los cuales se busca salvaguardar esa homogeneidad en todos sus estratos.

La mayoría de estas formas espaciales de laboratorio se preocupan -además de por los usos, las formas y los tamaños de parcelas- por la imagen como garantía de exclusividad: los edificios se visten con arquitecturas representativas que se convierten en reclamos icónicos, en contenedores donde se exponen metafóricamente los cualidades del uso contenido (alta tecnología, "imagen verde", lujo, carácter innovador, desenfadado, etc.); mientras el espacio público y la calle se convierte igualmente en un escenario, depurado y sanitizado, para la representación conjunta de las piezas. La idea subyacente sería la del "paraíso insular": una isla de perfección diferenciada del caos urbano.

Además de los paraísos insulares corporativos (A. Estevan), son formas características de los nuevos territorios metropolitanos las islas residenciales suburbanas, donde se han recluido las clases medias, los pequeños y grandes ganadores de la nueva economía, tras abandonar los tradicionales espacios urbanos de la ciudad consolidada huyendo de su complejidad social (al entender la diversidad como potencialmente peligrosa) y buscando el refugio en la predecible homogeneidad y uniformidad de los económicamente semejantes. Estas islas residenciales constituyen enclaves aislados, difícilmente accesibles (casi siempre sólo a través del vehículo privado), frecuentemente segregados del resto de la ciudad (separados por barreras de infraestructuras o vacíos), encerrados en sí mismos física (comunidades cerradas, condominios, countries o gated communities) o virtualmente (protegidos por dispositivos de seguridad y control).

Una segunda característica recurrente en las nuevas formas espaciales sería la progresiva pérdida de sus cualidades como lugares y su vinculación creciente con el territorio red. De este modo se privilegian las conexiones con el viario de alta capacidad o las grandes infraestructuras, mientras se marginan las conexiones locales o peatonales con el entorno inmediato. Ello provoca que se potencien los accesos y los recorridos en automóvil y que el entorno inmediato de la edificación se convierta exclusivamente en espacios de circulación o aparcamiento, sacrificando sus posibilidades de apropiación, su carácter habitable y la escala humana propia de los lugares de la ciudad tradicional. 
De estas dos características se deriva un ensimismamiento y un autismo urbano que resulta perfectamente coherente con la desvinculación local de los nuevos nodos urbanos y de su remisión a la totalidad de la ciudad o del territorio red: los elementos no se sitúan en un punto concreto en el espacio (más bien al contrario: se impiden, se niegan o se marginan las conexiones con el entorno inmediato) sino en la topología de una red que remite finalmente a un conjunto da mayor escala, en última instancia global.

\section{La reformulación permanente y traumática de la ciudad tradicional}

La ciudad tradicional se construyó bajo otros presupuestos -sociales, económicos, culturales, etc.- muy diferentes de los que hoy se han hecho hegemónicos. En las ciudades europeas, buena parte de esos tejidos -sobre todo las vastas periferias residenciales de bloque abierto en que se alojó masivamente la clase obrera y media del paradigma anterior- es entendida hoy como obsoleta, y abandonada al destino que parece reservarle el "mercado": alojar al contingente de los inmigrantes y a la fracción de los primitivos pobladores (población envejecida, con menores recursos, etc.) que han quedado atrapados en ellos desde el punto de vista inmobiliario por no poder permitirse el traslado hacia las nuevas zonas residenciales suburbanas de moda mencionadas anteriormente.

Por el contrario, algunos tejidos centrales conservan aún ciertos valores (centralidad, accesibilidad, representatividad, etc.) que los hacen deseables y atractivos para el "mercado", obligándoles a someterse a traumáticos procesos depurativos de "renovación urbana" que en realidad implican la simplificación de su complejidad y la selección de sus componentes urbanos (usos, habitantes, etc.) mediante la expulsión de la población original (elitización), la sustitución del uso residencial por el de oficinas (terciarización) o por el triplete formado por el comercio, el turismo y el ocio (transformación en parques temáticos de los centros históricos).

\section{El espacio de las redes}

Según M. Herce y F. Magrinyá (2002: 30), “se define como topología de redes la estructura formal del conjunto de puntos creada por la existencia de relaciones. Los puntos, origen de las relaciones, y las líneas, signo de su materialización, conducen a la consideración de una topología propia de cada red, expresada instrumentalmente a través de la teoría de grafos". "Las redes están generadas por la existencia de relaciones entre los puntos, pero la característica reticular esencial es que las relaciones se expresen a través de los flujos, sean de transporte, de información, o de energía. Éstas se manifiestan materialmente a través de las infraestructuras físicas de las redes" (op. cit: 29). 
Para V. Todaro (2008), "en los sistemas reticulares reales, en los cuales la importancia del nodo la da el número de conexiones que éste establece con los otros nodos, se pone de relieve el papel fundamental ejercido por los elementos de conexión en el funcionamiento del sistema. El valor del nodo no depende de sus características intrínsecas (o no solamente de ellas), sino del sistema de relaciones (conexiones) que éste posee y que son útiles no sólo para el funcionamiento de la red, sino también para la integración con otras redes. El nivel de atención, tradicionalmente centrado en la relación nodo/red, se traslada por tanto a la relación conexión/red, y al papel efectivo, a menudo infravalorado, que un sistema de conexiones puede desempeñar para el funcionamiento de las redes."

El espacio red derivado de las relaciones funcionales que se producen en el territorio contemporáneo es un espacio vectorial, conectivo, donde priman las características topológicas frente a la geometría euclídea, la unidireccionalidad frente a la tridimensionalidad del espacio de los lugares. Es un espacio unifuncional donde sólo se circula, en base a código pautado. Es un espacio inaccesible para las personas como tales, que sólo pueden participar en el mismo (circular) como sólidos en movimiento dentro de máquinas, con una velocidad de desplazamiento que altera los parámetros perceptivos del espacio tradicional, introduciendo nuevas reglas de visión cinética, secuencias, etc. (K. Lynch).

Entre sus propiedades, destacan la tendencia hacia la homogeneidad y la isotropía; a pesar de lo cual el despliegue real de las redes sobre un territorio concreto provoca una fortísima anisotropía: primero, estableciendo diferencias trascendentales entre puntos conectados y no conectados (efecto túnel, barrera, hiperconexión, etc.), segundo, porque al desplegarse sobre un territorio no vacío (en absoluto isótropo, sino condicionado por su medio físico y su sistema de asentamientos), se adapta desde la idealidad a la concreción geográfica e histórica de un territorio, induciéndolo y excitándolo de forma diferencial.

Estas redes pueden agruparse en dos grandes categorías: ${ }^{7}$

-Las redes de nodos hiperconectores, como los aeropuertos o el metro, redes cuyas líneas conectivas son irrelevantes espacialmente y de las cuales sólo tienen trascendencia espacial los nodos.

-Las redes de circulación, compuestas a su vez por canales de flujos y nodos, en las que las líneas tienen una presencia importante, por un lado como barreras, por otro como polarizadoras. La función de los Canales de Flujos (en adelante CCFF) consistiría en suministrar materia, energía e información a los organismos urbanos, donde esta se almacena y consume ${ }^{8}$ para permitir el metabolismo de estos artefactos

\footnotetext{
${ }^{7}$ División que corresponde a dos modos distintos de inducción del territorio: los nodos hiperconectores lo inducen en torno a puntos, las redes de circulación (canales y nodos) en torno a puntos y líneas.

${ }^{8}$ En este sentido es importante recordar la idea introducida por F. Ascher de la ciudad como máquina de almacenamiento o concentración de bienes (b), información (i) y personas (p), lo que denomina "bip".
} 
urbanos y sobre todo sostener el funcionamiento de las máquinas de acumulación económica mediante la transformación de esos recursos materiales y energéticos, con el concurso de la información concentrada en los territorios urbanos. Podemos dividir los CCFF en canales exclusivos y especializados de materia y energía para el metabolismo urbano, que denominamos Canales Metabólicos, y Canales de Transporte.

\section{Los Canales Metabólicos y las Máquinas de Metabolismo urbano}

Como señalaba J. M. Naredo, los requisitos necesarios para el funcionamiento metabólico de la ciudad implican la existencia de otros territorios que actúen como "áreas de apropiación y vertido" de los recursos ausentes en la ciudad y de "vertido" de los residuos en ella producidos. Estas relaciones parasitarias son reticulares y jerárquicas y pueden entenderse en términos de líneas o canales y nodos o máquinas de metabolismo. Así podemos hablar de Generadores y Máquinas de Apropiación de materia y energía (pantanos, centrales térmicas, nucleares, parques eólicos, canteras, etc.) que actúan como extensiones tentaculares de la ciudad hacia los territorios que depreda. Por otro lado, la necesidad de manipulación de estos flujos supone también la existencia de Máquinas de Combinación, Almacén o Manipulación de materia y energía (plantas y depósitos de almacenamiento de gases y combustibles, estaciones de potabilización de agua, subestaciones eléctricas,etc.); y por último, la necesidad de expulsión de los vertidos de la ciudad fuera de su entorno (una vez sobrepasada su capacidad de carga) se materializa en las grandes Máquinas de Vertido, tales como los vertederos, los emisarios marinos, las depuradoras, las plantas incineradoras, etc., o en las pequeñas máquinas individuales que emplean la atmósfera o el territorio como sumidero inmediato.

La conexión entre estas grandes máquinas de apropiación y vertido para suministrar la materia y energía requerida por el metabolismo urbano se realiza mediante canales exclusivos y especializados por los cuales sólo circulan exclusivamente flujos de un mismo tipo, como las redes de abastecimiento de agua, saneamiento, red eléctrica, gasoductos, oleoductos, etc.

\section{Los Canales de Transporte}

Los canales de transporte como las autopistas, vías férreas, carreteras, etc., son canales versátiles, no exclusivos, en cuanto a la diversidad de flujos que pueden circular por ellos (recursos humanos, materiales y energéticos), siendo especialmente significativos como soporte de la movilidad de recursos humanos y personas por el territorio, portadoras en definitiva de información y know how, inputs imprescindibles para las condiciones en que se desenvuelve actualmente la acumulación y fundamentales para la integración de los mercados de trabajo y consumo metropolitanos. 
Como señala F. Ascher (2004), estos canales han sustituido el concepto de proximidad por el de accesibilidad: "la proximidad, que fue uno de los principios de la ciudad y uno de los elementos determinantes de su potencial económico y cultural, ya no precisa contigüidad". Así, la aglomeración relacional, la tele-aglomeración o la dispersión concentrada se convierten en las claves funcionales del sistema metapolitano (Ascher 2004) al permitir el funcionamiento integrado de un sistema que espacialmente es discontinuo, fragmentario y disperso.

Estos CCFF caminan conceptualmente hacia la simultaneidad (mediante la aceleración en términos de P. Virilio, que implica transformar en hiperconexiones las conexiones ya existentes) y la ubicuidad, pues la red física de canales de transporte tiende a ser cada vez más invisible (en términos conceptuales, que no visuales ni de impacto físico sobre el territorio) ya que no puede hacerse inmaterial por su propia naturaleza. En la actualidad, los desplazamientos "se miden" en términos temporales y no espaciales, anulándose el interés del desplazamiento en sí, y pretendiendo hacer desaparecer el espacio intermedio en favor de las terminales o puertas de origen y destino: el resto es ya sólo tiempo, tiempo que hay que ocupar convenientemente. El espacio se quiere hacer tiempo. ${ }^{9}$

Además, los CCFF tienden también a ser convertidos en canales hiperespecializados de transporte, suprimiendo el resto de funciones no relacionadas con el transporte que puedan interferir con ésta; lo cual les diferencia radicalmente respecto de la calle corredor tradicional, soporte de múltiples funciones además del transporte. Ahora se trata de optimizar al máximo su función haciendo abstracción de todo aquello que no sea la propia lógica del itinerario: los canales son sólo espacios funcionales para llegar a algún lugar, pero no son lugares en sí mismos; apareciendo completamente desvinculados de los lugares y paisajes que atraviesan.

Por otra parte, la forma funcional óptima de los CCFF busca una mejor circulación de los flujos y una mayor autonomía e independencia en los desplazamientos. Esta forma ya no es la de una red topológicamente jerarquizada como lo fue la red radial o radioconcéntrica de las viejas áreas metropolitanas fordistas, sino una retícula, mallada e isótropa, con una autosimilaridad fractal y una jerarquización estructurada de las líneas de conexión (canales de primer orden, de segundo, etc), cuyo modelo ideal es el de la "ciudad dispersa norteamericana" (Houston, LA, Phoenix) y como tal subyace en el despliegue de redes viarias en la mayor parte de los territorios metropolitanos avanzados.

\footnotetext{
${ }^{9}$ La consideración del viaje como intervalo temporal y no como desplazamiento espacial a través de una serie de lugares, fue inaugurada por Phileas Fogg en la "La vuelta al Mundo en 80 días", que puede considerarse como el primer viaje moderno. Como escribe Julio Verne (1873; Edición inglesa, 1994: 35) "he was not travelling, he was merely describing a circumference. He was a solid body moving through an orbit around the terrestrial globe, in obedience to the laws of rational mechanics". Phileas Fogg -un personaje literario- habría sido el primer habitante de la ciudad basada en el tiempo, no en el espacio.
} 
Pero paradójicamente, estas redes isótropas sólo garantizan y posibilitan la circulación homogénea de flujos por el territorio, no la isotropía de éste. La lógica del transporte incrementa las discontinuidades, y los canales suponen fuertes barreras territoriales que implican la inaccesibilidad y la falta de permeabilidad transversal, mientras que las estaciones o los puntos de parada a lo largo de los canales concentran la accesibilidad, multiplicando y polarizando el desarrollo urbano en torno a los lugares de intercambio y/o acceso, vaciando o desvalorizando los territorios intersticiales.

Por ello, el territorio es -hoy más que nunca- discontinuo o no homogéneo, sobre todo en términos significativos o cuantitativos: aparecen vacíos, intersticios junto a áreas que concentran la intensidad y absorben la mayoría de los flujos. La anisotropía es especialmente patente en cuanto a la distinta capacidad de atracción del territorio: en este sentido, la potencia atractiva de algunos canales excita al territorio sobre el cual discurre, induciendo al desarrollo de éste, fenómeno que denominamos polarización; mientras otros canales tienen un efecto repulsivo, actuando como bordes o fronteras.

\section{De las intersecciones de los CCFF a los Intercambiadores}

Por su parte, los nodos de las redes de circulación de flujos sólo resultan significativos en el caso de que permitan el intercambio de flujos (por ejemplo: un nudo de autopista, por permitir el trasvase entre una red secundaria y una primaria; o un intercambiador urbano que permite los intercambios entre autobús, metro, coche y flujos peatonales) o su manipulación, reduciéndose al papel de meras intersecciones en caso contrario (cruce de vías de tren, cruce de autopistas a distinto nivel, etc.).

Si los canales de las redes de transporte tienen capacidad de excitación sobre el territorio, ésta se multiplica en torno a los Nodos de Intercambio, terminales, entradas y salidas que permiten el intercambio modal en los desplazamientos personales, el transvase entre los distintos canales, y, sobre todo el trasbordo entre el espacio red y el espacio de los lugares, pues es aquí donde los cuerpos en movimiento de los CCFF recuperan su movilidad humana natural. A estos puntos -puertos, aeropuertos, estaciones de tren y metro, etc.- les denominamos intercambiadores y se han convertido en las nuevas puertas conceptuales de la ciudad con una fortísima potencialidad urbana.

\section{La expansión reticular: reticulación+polarización}

La expansión reticular es el proceso de crecimiento más característico de la ciudad y del territorio contemporáneos, respondiendo como se ha comentado a esa morfología reticular del actual régimen de acumulación predominante que tiende a integrar los territorios y a organizarlos en nodos de acumulación y líneas o canales de circulación de flujos entre éstos, permitiendo el funcionamiento unitario y conjunto de un organismo espacialmente disperso y fragmentado en el que realmente carece ya de 
sentido plantear la continuidad o la discontinuidad, pues la lógica conjunta, la estructura relacional real, es aportada por las redes.

Como señalan M. Herce y F. Magrinyá (2002: 11), "la topología de esas redes permite crear un nuevo espacio con discontinuidades espaciales que no son siempre conexas; los límites y fronteras administrativas areolares son desbordadas por las extensiones de la actividades y las nuevas fronteras vienen definidas más por el hecho de si un punto está o no conectado a la red. De una visión areolar inscrita por contigüidad, [se] tiende a una visión reticular, caracterizada por la conexión e inscrita en la fragmentación; de un modelo definido por la noción de distancia al centro se tiende hacia otro modelo que gira en torno de la noción de velocidad de conexión a la red, donde los puntos con mayor conectividad son los privilegiados respecto al conjunto de los puntos del territorio". Por lo tanto, la reticulación posibilita el funcionamiento de las redes de acumulación sin necesitar de la proximidad, estableciendo vínculos a distancia para permitir un funcionamiento integrado. Así, la reticulación resulta ser una forma peculiar de aglomeración (una tele-aglomeración relacional) que sustituye la proximidad por la accesibilidad y que por tanto hace banal la distinción dentro el territorio red maduro entre las formas agregadas y las dispersas, ante la extraordinaria importancia que adquiere la conexión o desconexión como criterio frente al clásico de la continuidad o la discontinuidad.

La reticulación es también un signo inequívoco de la implantación del modelo físico hegemónico propio del nuevo régimen de acumulación, por lo que debemos ver ésta y la construcción de infraestructuras a todas las escalas como un proceso de conexión territorial con la nueva lógica funcional de la globalización.

Como la reticulación es un proceso espacial íntimamente asociado a líneas y retículos, fuertemente vectorial y direccional, introduce intensas anisotropías en los territorios donde se despliega, induciendo y generando en torno a sus líneas y a sus intersecciones nuevas posibilidades de crecimiento de tipo polar (lineal o puntual). Es por ello que la polarización resulta ser un segundo momento en la expansión reticular: una vez desplegada la reticulación, las redes generan tensiones, atraen, inducen crecimientos, excitan territorios, lineal o puntualmente, ${ }^{10}$ "como si la centralidad consistiera ahora en la pertenencia a la red y a la especialización espacial" (A. Font, C. Llop y J. Ma Vilanova, 1999: 7).

\footnotetext{
${ }^{10}$ En realidad y como también recuerdan A. Font, C. Llop y J.M ${ }^{\text {a }}$ Vilanova (1999: 22), "esta lógica de crecimiento tiente también algunos antecedentes en períodos anteriores. De hecho, las implantaciones a lo largo de los ejes territoriales y nodos de intercambio (por ejemplo, nudos viarios, puerto-ferrocarril, etc.) se producen desde los inicios de los procesos de formación y extensión de las actividades urbanas sobre los diversos territorios, en implantaciones relacionadas fundamentalmente con la industria o con determinados tipos de servicios y equipamientos". Remontándonos más atrás y generalizando, no cabe duda de que el crecimiento dispersivo lineal clásico a lo largo de carreteras y caminos ya estaba polarizado en mayor o menor medida (filamentos).
} 
Esta idea es confirmada por M. Herce y F. Magrinyá: "la nueva organización territorial produce puntos privilegiados asociados a las vías de circulación y a la interacción de los límites, que entran en competencia con las centralidades tradicionales. El poder se manifiesta precisamente en el control de los puntos de cruce de los límites y de las vías" (M. Herce y F. Magrinyá 2002: 17).

En esta excitación, las formas de crecimiento polarizado buscan (y compiten por) las ventajas derivadas de la hiperaccesibilidad de los canales, los nodos o los intercambiadores, la posibilidad de hiperconexión inmediata con la gran estructura del sistema reticular, y otras características menores como la representatividad o la visión desde los canales.

Así pues, la expansión reticular propiamente dicha es consecuencia de la combinación de dos procesos: primero la reticulación, el despliegue infraestructural; después la inducción del crecimiento polarizado sobre las líneas o los nodos de las redes. Pero además de esta secuencia propia de la expansión reticular, que es la que generalmente produce el desligue del territorio red al operar sobre el vacío, conviene recordar que la reticulación en muchos otros casos no se ha dado sobre ningún vacío, sino sobre un territorio que estaba ya intensamente construido antes de ser reticulado, un territorio complejo compuesto por mosaicos, patchworks y collages de aglomerados yuxtapuestos, así como por archipiélagos de islas dispersivas y otras formaciones. En este caso, la superposición de la reticulación habría inducido sobre los territorios construidos una excitación o polarización a posteriori, lo que implica haberlos dotado de nuevos significados, transformando completamente su funcionalidad y su modo de integración en un nuevo sistema tele-aglomerado.

\section{El campo rizomático de los flujos inmateriales}

Hasta la aparición del telégrafo en el siglo XIX y salvo ciertas excepciones o curiosidades anecdóticas, las principales fuentes de información eran la transmisión oral directa o la escrita, de modo que la información o bien circulaba con el hombre (mensajero, cartero, etc.) o, como máximo, lo hacía sobre los medios de transporte disponibles (caballos, diligencias, etc.). De este modo, comunicación y transporte estaban íntimamente unidos, y las redes y líneas de circulación eran las mismas para la circulación de mercancías, bienes e informaciones. Pero la aparición de nuevas tecnologías de la información y la comunicación han permitido separar definitivamente la circulación de la comunicación, posibilitando la transmisión de comunicaciones y el intercambio de información a la velocidad de la luz, eliminando la necesidad de transporte para intercambiar información.

Durante la segunda mitad del siglo XX, con la extensión de la cobertura y la popularización de la radio, el teléfono y la televisión, y en la última década, tras el desarrollo de Internet, la telefonía móvil, los satélites, etc., se ha extendido a escala planetaria la cobertura del campo rizomático de los flujos inmateriales, que permite (sin 
apenas infraestructuras visibles, y gracias a sofisticadas tecnologías de emisión y recepción) el acceso a una serie creciente de contenidos que antes eran patrimonio exclusivo de lo urbano.

Nos interesa ahora considerar este despliegue como hipotético inductor de una nueva forma de crecimiento urbano, que denominaríamos disolución, y que correspondería a desarrollos puntuales tipo "confetti" floreciendo espontáneamente sobre territorios no urbanos (en el medio natural o rural), una suerte de nueva dispersión o difusión puntual a base de nodos individuales (nómadas en el extremo utópico de Superstudio $)^{11}$ conectados al campo rizomático, sin buscar ni necesitar ningún tipo de estructura urbana previa. Como ya se dijo, esta forma de crecimiento se basaría en el entendimiento de lo urbano como una serie de significados o contenidos (cultura, sistema de valores, intercambio de ideas, etc.) que actualmente pueden ser soportados por el campo rizomático, y que por tanto ya no residen exclusivamente en la ciudad, sino que son potencialmente accesibles desde cualquier sitio, gracias a la ubicuidad y omnipresencia del campo rizomático. Pero para que uno de estos nodos pudiera considerarse como estrictamente derivado de la disolución, sería necesario que realmente no necesitase de la ciudad como infraestructura material, esto es, que fuera autosuficiente en términos de flujos materiales y energéticos, en cuyo caso sería posible afirmar que dicho nodo no precisaría de las infraestructuras físicas de concentración y distribución de flujos propias de los aglomerados urbanos y que sólo accedería a los contenidos inmateriales urbanos a través del campo rizomático.

A pesar de su recurrencia en ciertos discursos cuasi apocalípticos, no cabe duda de que ésta no parece una forma de crecimiento generalizable en la actualidad, más allá de algunos posibles ejemplos excepcionales de carácter individual o de ciertas comunidades de pequeño tamaño, sobre todo porque para ser auténtica requeriría de una autosuficiencia tal que permitiera constatar efectivamente su independencia material respecto de lo urbano. En realidad, y a falta de esta autosuficiencia material, cualquier tipo de desarrollo continuará necesitando de conexiones físicas que le suministren recursos y materiales desde otros territorios a través de los nodos de distribución, combinación y reelaboración que son las ciudades, por lo que no parece verosímil que el despliegue del campo rizomático vaya a posibilitar la disolución de la ciudad, como se anunciaba en la utopía de Superstudio.

Sin embargo, y como ocurriera también con la polarización a posteriori, el despliegue del campo rizomático se ha producido sobre un territorio ya construido, teniendo un impacto trascendental sobre éste: reforzando la intensidad de los contenidos

\footnotetext{
11 Las imágenes más inmediatas de la disolución serían las de un teletrabajador "pinchando" o conectándose con el campo rizomático en cualquier punto, o las de una persona utilizando las posibilidades multimedia de éste a través de un móvil; pero estas visiones no serían más que fragmentos parciales de esa disolución total que imaginó ya el grupo italiano Superstudio en los años 70 , un mundo de nómadas sin objetos habitando todo el territorio del planeta, tupido por una retícula, no infraestructural, sino de significados urbanos. En este sentido debe verse la serie de imágenes "Living". Recientemente Peter Lang y William Menking han publicado "Superstudio: life without objects", Milán, 2003.
} 
urbanos en la ciudad, y empapando de consignas culturales urbanas el medio rural. En este sentido puede decirse que este despliegue ha arrasado prácticamente con las culturas autóctonas, empapando de valores y significados urbanos todo el territorio cubierto por el campo rizomático, urbanizando las conciencias.

La urbanización de la conciencia es el mensaje final del despliegue del campo rizomático: la uniformización y el condicionamiento del deseo comunitario hasta anularlo e identificarlo con lo que debe ser deseado en la nueva comunidad de consumo planetario, el reforzamiento de los lazos de pertenencia a esta nueva comunidad, la hiperorganización del tiempo, etc.

Además de esta urbanización mental, el despliegue del campo rizomático tiene otro sentido físico mucho más inmediato, pues al ofrecer la posibilidad de acceso a determinados contenidos inmateriales y servicios urbanos a través del campo (desde ver una película a acceder a las novedades discográficas, asistir a una subasta, realizar un cursillo de idiomas, conocer personas, visitar museos, realizar operaciones financieras, consultar fondos de bibliotecas, comprar en cualquier punto del planeta, etc.) que antes sólo eran accesibles mediante la proximidad, la presencia o el contacto físico, la posibilidad de acceso ubicuo debilita aún más la dependencia de los asentamientos con respecto a los aglomerados urbanos, relaja los lazos de unión entre las estructuras urbanas, o, lo que es lo mismo (y esto es lo más relevante) refuerza sinérgicamente la dispersión o la expansión reticular. Más concretamente, la posibilidad de circulación de información y conexión/comunicación ${ }^{12}$ a través del campo rizomático, sin precisar el movimiento de los portadores de esta información (personas) o la presencia de éstas, detrae de la ciudad una de sus principales funciones como espacio de acumulación/almacenamiento de información y como lugar de encuentro e intercambio de ideas (F. Ascher). Los espacios públicos y los lugares centrales han dejado de ser los únicos espacios capaces de albergar estos intercambios y comunicaciones, que pueden realizarse ahora en el ciberespacio o a través del campo rizomático.

\section{Conclusiones}

Buena parte de los discursos contemporáneos sobre la ciudad insisten en presentar los efectos espectaculares y mediáticos de algunas resplandecientes transformaciones urbanas de carácter emblemático, casi siempre orientadas a la renovación de ciertos tejidos centrales o al despliegue de las nuevas infraestructuras y de los nuevos nodos de

${ }^{12}$ En palabras de M. Herce y F. Magrinyá (2002:11) : las redes de telecomunicación "plantean un nuevo modelo de jerarquización del territorio en el que el principio de proximidad tiende a debilitarse a favor de la noción de "conectividad", por su potencial de conexión de puntos muy lejanos, por su mayor capacidad de romper esa fricción espacial debida a la distancia". 
acumulación: parques empresariales, comerciales, etc. Sin embargo, frecuentemente se obvian los efectos colaterales de dichas operaciones: la destilación y simplificación de la urbanidad que conllevan la mayoría de los procesos depurativos de "renovación urbana" (expulsando a los usos y la población más débil), la falta de relación entre las nuevas formas espaciales y las estructuras urbanas existentes (de modo que los nuevos fragmentos de ciudad son piezas segregadas y autistas vinculadas con la totalidad única y exclusivamente a través de las redes viarias), la banalización del espacio público y su progresivo vaciamiento de funciones espontáneas en aras de su especialización comercial o turística, etc.

Pero quizá lo más peligroso sea el abandono conceptual del resto de los tejidos de la ciudad, especialmente de las zonas residenciales que ocupan la mayor parte de su superficie y donde habita la gran mayoría de sus habitantes. Canalizar las inversiones hacia las grandes infraestructuras, los proyectos emblemáticos o los relucientes núcleos direccionales de conexión con la globalización supone detraer recursos para el mantenimiento y el funcionamiento diario de esa "ciudad cotidiana", que es donde vive la mayoría de los ciudadanos y especialmente los más débiles.

De este modo, bajo las nuevas formas espaciales contemporáneas no se esconde sino el viejo discurso de la eficiencia y de la competitividad, reformulado para adaptarse a los requerimientos espaciales de la última mutación capitalista, en detrimento de los ideales de la equidad y la justicia y del nuevo paradigma de la sostenibilidad. 


\section{Bibliografía}

Ascher, Frederic (2004), Los nuevos principios del urbanismo, Alianza Editorial, Madrid.

Choay, Françoise (1994), Le régne de l"urbain et la mort de la ville, Catálogo La Ville, Centro G. Pompidou, París.

Eizaguirre Garaitagoitia, Xavier (2001), La construcción del territorio disperso. Taller de reflexión sobre la forma difusa, Edicions UPC, Barcelona.

Font, Antonio, Llop, Carles, y Vilanova, Josep María (1999), La construcció del territori metropolitá: Morfogènesi de la regió urbana de Barcelona, Ed. Mancomunidad de Municipios Metropolitanos de Barcelona, Barcelona.

Herce, Manuel, y Magrinyá, Francesc (2002). La ingeniería en la evolución de la urbanística, Edicions UPC, Arquitext 28, Barcelona.

Naredo, José Manuel (2000), "Ciudades y crisis de civilización”, Revista Documentación Social, $n^{\circ} 119$, Cáritas Española, Madrid.

Solá Morales i Rubió, Manuel (1997), Las formas de crecimiento urbano, Edicions de la UPC, Barcelona.

Todaro, Vincenzo (2008), "Procesos de integración entre redes ecológicas e instrumentos de planificación”. Cuadernos de Investigación Urbanística, $n^{o} 54$. Instituto Juan de Herrera, Madrid.

Veltz, Pierre (1999), Mundialización, ciudades y territorios, Ariel, Barcelona. 